\title{
FAMILIAL CEREBRO-MACULAR DEGENERATION AND ATAXIA
}

\author{
J. B. FOSTER AND T. T. S. INGRAM \\ From the Department of Neurology, Royal Victoria Infirmary, Newcastle upon Tyne, \\ and the Department of Child Life and Health, University of Edinburgh
}

Ataxia and macular degeneration have already been described occurring alone and in association in different members of the same family but the number of recorded cases is small (Wyburn-Mason, 1943; Walsh, 1957).

In this paper we describe the clinical findings in a child of 2 years, his mother, and his maternal grandmother, all of whom showed macular degeneration and ataxia (Fig. 1).

\section{FAMILY HISTORY}

CASE 1 Colin D. (generation $E$ in Fig. 1), born on 9 September 1958, of non-consanguinous parents, was admitted to the Royal Hospital for Sick Children under the care of Professor R. W. B. Ellis in August 1960 with the complaint that since February of that year he had been increasingly unable to walk.

The patient was the result of a full-term spontaneous delivery after an uncomplicated pregnancy and had a birth weight of $7 \mathrm{lb} .13 \mathrm{oz}$. He cried immediately after birth and thrived well. He was vaccinated and immunized against diphtheria, whooping cough, and poliomyelitis, and had no serious illness apart from bronchitis in March 1960 which was treated at home with penicillin injections, and from which he made a good recovery. $\mathrm{He}$ sat up with a pillow as support aged 4 months and alone at 6 months. He was walking alone at 11 months, and though he had no words until 17 months he was considered by his mother and the rest of the family to be an advanced child in other respects.

In February 1960 he fell and hit his head and required two stitches in the forehead. From that time onward his speech ceased to develop, and his parents observed that he was beginning to be tremulous when he reached for objects. He became more and more unsteady, falling progressively frequently, and by late July 1960 had stopped walking independently, though he still walked with the support of furniture, staggering from piece to piece. His play seemed to have become less enterprising and less imaginative. By the end of August 1960 he had ceased to walk even with support and sat or lay on the floor at home most of the day. He could not feed himself at all and made noises instead of uttering even single words. His appetite was variable but his weight seemed to be well maintained.

On account of these complaints he was admitted to

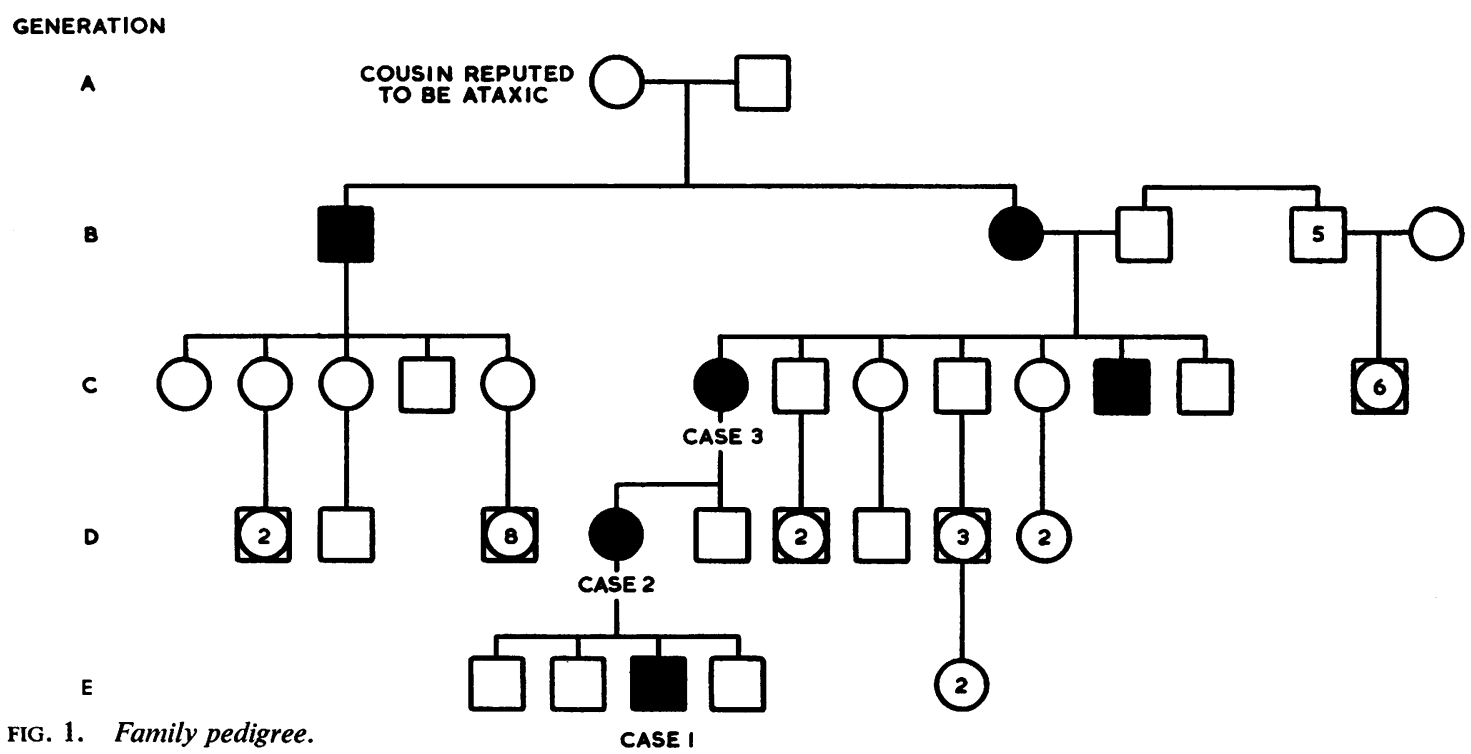

FIG. 1. Family pedigree. 
hospital and was found to be quiet, lethargic, and miserable. He took very little interest in his surroundings and was obviously disabled by his illness. He showed marked intention tremor and clumsiness when handling toys and was unable to support himself in the sitting position for more than a few minutes without becoming exhausted. He could not stand even with support. The major neurological findings at this time were bilateral pigmentation of the retinae with generalized muscular incoordination, intention tremor, hypotonia, and marked ataxia. Biceps, triceps, supinator, knee, and ankle jerks were all very sluggish but symmetrical. The plantar responses were flexor. No abnormalities of skin sensation were noted. Special investigations were unrewarding.

While in hospital he appeared to become more interested in his surroundings and less apathetic. He became steadier and within 10 days of admission was able to walk round his cot supporting himself with his hands. He was discharged after three weeks with a provisional diagnosis of cerebro-retinal degeneration. After his return home, however, he relapsed, played less and less and took little interest in his surnoundings. He ceased to try to walk or crawl and sat or lay on the floor at home most of the day.

On account of his deterioration he was readmitted on 27 October. He was found to be an apathetic child with limited attention span and little interest in his environment. No speech or comprehension of speech was apparent, though there appeared to be no actual impairment of hearing. He responded to tones of voice but not to content of speech. He sat looking about him in a rather blank fashion most of the time, turning his head from side to side. There was a continual slight irregular head and trunk tremor. He handled toys but tended to grope for them before finding them, using either hand.

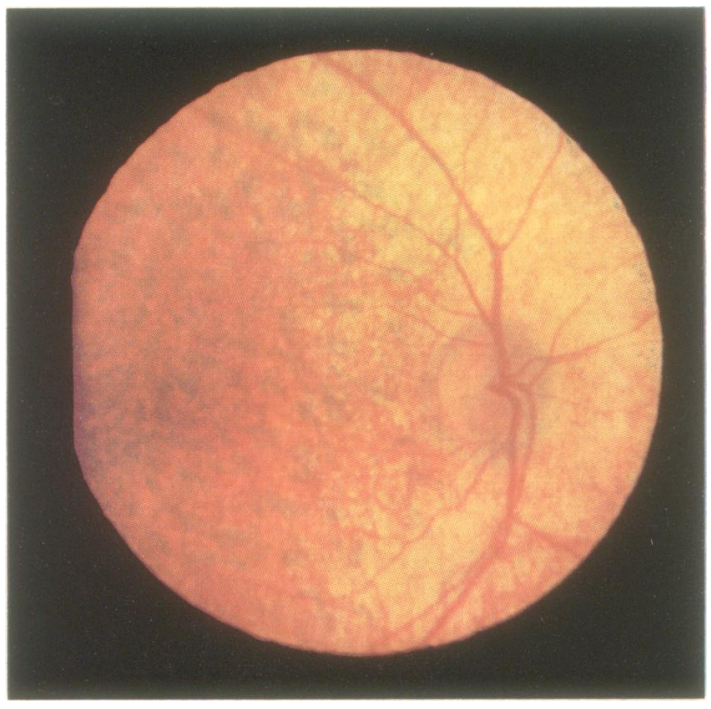

FIG. 2a. Right retina (Case 1).
His vision seemed defective. Though he could sit without support he showed considerable head tremor while he did so. He could not stand without support but could stand fairly steadily with support. Sense of smell was normal. The fundi showed gross abnormalities. There was marked dark brownish pigmentation in clumps of small globule-shaped masses, maximal peripherally and in the region of the maculae bilaterally. The grounds of the fundi were completely altered by this pigmentation, the small globules of pigment completely replacing the normal background. The vessels were abnormal, the arteries being very slender, short, and tenuous and not being easily found in the circumferential fundus. The veins were less tenuous than the arteries. The discs were clear and not swollen. They were not enlarged, and the margins were round and regular, but the colour was abnormal, being a yellowish fawn (Fig. 2). Visual acuity was certainly defective, though he could see objects to the size of a finger, occasionally with some difficulty and at other times apparently fairly easily at a distance of about 3 feet. Pupils were circular, regular, and approximately equal though they reacted rather sluggishly to light and accommodation. The eye movements were full and equal in all directions and conjugate. There was no true nystagmus but when he did look at objects he did seem to show small irregular movements of the eyes until he could fix on them. The face was symmetrical and hearing appeared to be within normal limits. Swallowing, palatal and tongue movements were normal. Thereb was a generalized loss of subcutaneous fat, and muscle? bulk was difficult to assess but no localized asymmetrica $\mathbb{B}-$ wasting was detected. Tone was markedly reduced in alp $\mathbb{D}$ four limbs, and there was hyper-extensibility of all joints especially in the digits. Power was moderately reduced in all four limbs, and coordination was grossly impaired,

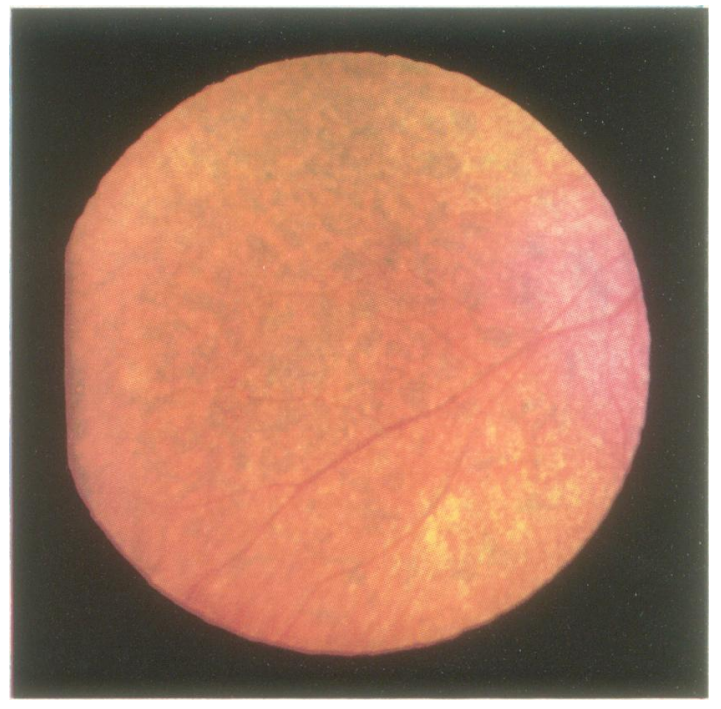

FIG. 2b. Intero-lateral region right retina (Case I). 
the fingers being used together as a unit in both hands. He did not use the thumbs to any significant extent even when reaching for objects. When he did reach for objects, particularly as his hands approached them, marked irregular tremulous movements were observed, and these comprised an irregular slow intention tremor approximately symmetrical in its severity. No other involuntary movements were present. When stood up in the erect position he could maintain his posture if steadied at the level of the lower ribs and could make reciprocal walking movements, though he was grossly ataxic. The biceps, triceps, and supinator jerks were symmetrical but very sluggish, the knee and ankle jerks being a little brisker. The plantar responses were flexor. The abdominal reflexes were present. No abnormalities of skin or joint sensation were demonstrated. Apart from a mild hypochromic anaemia, haematological findings were not abnormal. In particular vacuolated lymphocytes could not be demonstrated. Cerebrospinal fluid was obtained by lumbar puncture, the pressure being $80 \mathrm{~mm}$. of spinal fluid and the response to jugular compression quite normal. It contained no cells and $15 \mathrm{mg}$. of protein per $100 \mathrm{ml}$. The Lange curve was 0111100000 . The Wassermann reaction was negative. An electroencephalogram showed a slight generalized excess of slow wave activity. The serum cholesterol was $300 \mathrm{mg}$. per $100 \mathrm{ml}$. Serum proteins, serum amino-acid chromatograph, blood urea, nitrogen, serum copper oxidase, serum iron, serum creatinine, and creatinine clearance were within average limits. The toxoplasmosis dye test was negative. The electrocardiogram showed no abnormality.

He was discharged on 26 November 1960 . During the following weeks he became progressively less active. His mother observed that his vision seemed to be deteriorating and he could no longer see well enough to reach for small objects. He ceased to play and his movements seemed more tremulous. By the beginning of January 1961 he could no longer sit without support, and on examination on 9 January 1961 he was found to be unsteady even when sitting with support. His head tremor was accentuated and he was extremely apathetic. He died suddenly during the night of 11 February 1961. Most regrettably it was not possible to obtain a necropsy examination.

CASE 2 Mrs. G. D. (generation D in Fig. 1), aged 25, is mother of the patient. She was born after an uncomplicated pregnancy and labour, was thought to be normal in the neonatal period and developed normally. Her school progress in the local elementary school had been quite average, and she was an active adolescent and young adult. She had measles, mumps, and chickenpox in her school years. At the age of 15 when she left school to become a dressmaker she developed 'migraine headaches'.

At the age of 19, four days after the birth of her first child, she developed a raised temperature and was isolated in the maternity hospital for fear of spread of infection. In her 'solitary confinement' she read more than she would otherwise have done and observed that after 15 or 20 minutes' reading print became blurred and disappeared in the centre of the visual field, so that although she could see the writing at the edges of the page she could not see the print at which she was looking. Bright light seemed to hurt her eyes and made them water excessively, to the extent that the nurses attending her used to ask why she was crying. The watering was severe for about one week and then gradually diminished, but it never disappeared completely, and in the summer in a bright light her eyes still begin to water. The eyes are no longer painful, though they were when they first began to water in the maternity hospital. She still finds that in bright light 'they screw themselves up'. In the ensuing six years there has been a progressive failure of vision. By 1956 she found that there was a constant defect of central vision, so that she could not see any point on which she fixed though she could see all round it. By 1957 sewing had become much more difficult and less neat. She could read only for five or 10 minutes before the central defect became so great that all reading was impossible, and though she still managed to do all her housework and to mend the children's clothes, it was with increasing difficulty. She now sees better in the dark than in bright light, and finds bright sunlight extremely trying but she has observed no other signs or symptoms, and claims that she is neither unsteady nor clumsy. She has never had abnormal sensations in the limbs nor disturbances related to bowel or bladder. Her periods are regular.

On examination she was a vivacious, attractive young woman without evidence of intellectual defect. No skeletal deformities were noted. Her sense of smell was normal. The optic discs were yellowish, but apart from their colour the discs were not strikingly abnormal. The vessels in both fundi were strikingly deficient in number and fullness, there being a marked impoverishment of vessels in the outer retinal fields bilaterally. The visual acuity was $\mathbf{J} 2$, uncorrected, bilaterally. The fields showed a marked enlargement of the blind spot bilaterally to confrontation, but there was no peripheral defect. The pupils were round, equal and regular, reacting normally to light and accommodation. The eye movements were full but accompanied by nystagmus in all directions, especially on upward gaze. Power was good in all four limbs and there was full range of active and passive movement. Finger-nose tests were well performed bilaterally, but not quite so accurately on the left as the right. Rapid alternating movements of the fingers, hand patting, and alternate supination and pronation were well performed bilaterally. Heel-knee tests were slightly jerkily performed on each side, and she was less good with the left leg than the right, but she could waggle her toes freely. Stance was normal but when the feet were close together she swayed slightly, and Romberg's test was positive. When she walked with the eyes shut, either forwards or backwards, she tended to deviate slightly to the left and she broadened her walking base. The knee and ankle jerks were definitely increased, and though the plantar responses were flexor the Hoffman responses were positive. Sensory findings showed no defect of light touch, pin-prick, hot or cold sensation, and vibration and position senses were normal. Two-point discrimination was normal.

Serum lipoproteins were as follows:-Total lipid $934 \mathrm{mg}$. \%, total esterified fatty acid 382, lipid phosphorus 12.4, phospholipid 322, cholesterol $326 \mathrm{c} / \mathrm{p}$ 


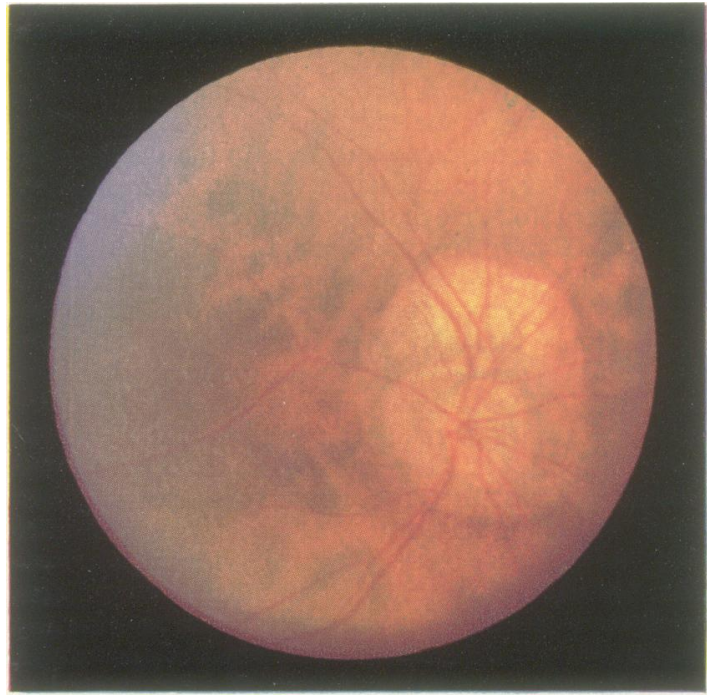

FIG. 3a. Right retina (Case 3).

$1.01, \gamma$-lipoprotein $113, \beta$-lipoprotein 492 , and $a$-lipoprotein 329.

CASE 3 Mrs. G. H. (generation C in Fig. 1), mother of Case 2, was investigated under the care of Dr. Henry Miller in the Royal Victoria Infirmary, Newcastle, at the age of 45. As far as she knows she was born after an uncomplicated pregnancy, labour, and delivery and was a normal infant and a healthy child. At the age of 22 she had first noticed deterioration of her vision, and this had progressed slowly since that time for seven years until in 1953 she observed, in addition, unsteadiness. She noted that she was 'staggering about like a drunken man'. The unsteadiness was of gradual onset, and she never actually fell. It was particularly noticeable when she tried to turn round. At about this time too she noticed occasional slurring of her speech and transient black shadows in front of her eyes. She was seen by Dr. Henry Miller in September 1954. She deteriorated further thereafter, her speech becoming more slurred but there was no disturbance of hearing, no feeling of dizziness or stiffness of the limbs.

On examination in the ward she was found to be rather a pale woman with no evidence of intellectual deterioration or mood change, and her memory was good. Speech showed a cerebellar type of dysarthria. The fundi showed some chronic choroidal changes involving the anterior region of the fundi. This, however, did not explain the partial loss of central vision. Discs did not show any obvious optic atrophy but in the right eye (Fig. 3) the retinal vessels were attenuated. Visual acuity was $6 / 36$ both eyes. On refraction, she was myopic with the left eye, and there was a divergent squint with some amblyopia. The right disc showed a large myopic crescent.

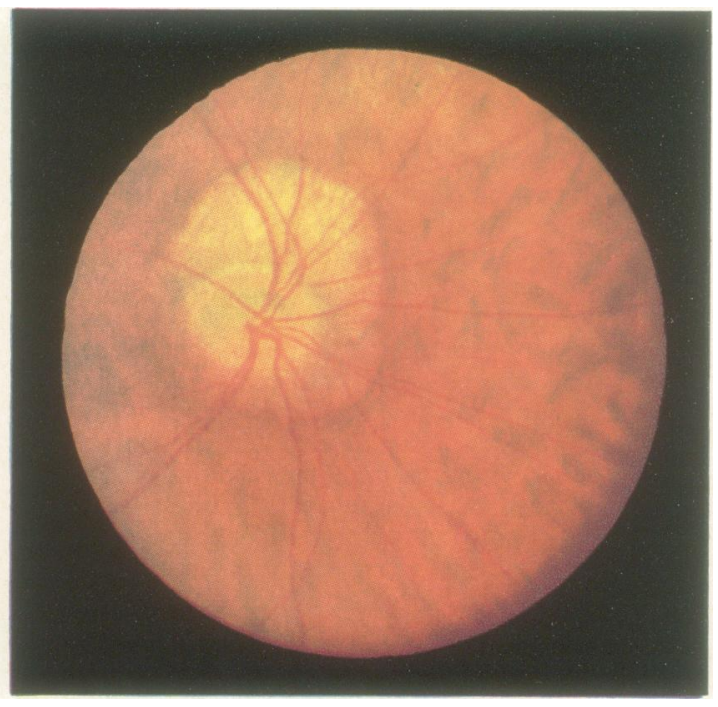

FIG. 3b. Right retina (Case 3).

The right visual field showed an upper nasal quadrant defect with a small central scotoma. Full external ocularo movements were present, though there was an unsustained $\mathbb{D}$ phasic grade I nystagmus. No other cranial nerve abnormality was noted. Upper and lower limbs showed no wasting, abnormal movements, or increased tonus. Slight symmetrical intention tremor in the upper limbs was contrasted with gross cerebellar type tremor in the lower limbs, though the Romberg sign was negative. There was no sensory defect to pin-prick, vibration, temperature, light touch or appreciation of joint position. Two-point discrimination was accurate. The reflexes were rather increased in all four limbs, though the plantar reflexes were flexor. Examination of the cardiovascular, respiratory, and alimentary systems showed no abnormality. A lumbar puncture was performed and showed a clear colourless fluid with a pressure of $\mathbf{7 5}$ millimetres of spinal fluid, two cells per cubic millimetre, protein $25 \mathrm{mg}$. \%. The Wassermann and Kahn reactions were negative. The Lange curve was 0000000000 . The blood examination showed only a mild hypochromic anaemia. A chest radiograph showed no abnormality. Serum lipoproteins were as follows:-Total lipid $886 \mathrm{mg}$. \%, total esterified fatty acid 279 , lipid phosphorus 11.4 , phospholipid 296, cholesterol $339 \mathrm{c} / \mathrm{p} 1 \cdot 15, \gamma$ lipoprotein 139, $\beta$ lipoprotein 455, and $a$ lipoprotein 292.

\section{FAMILY HISTORY}

In view of the presence of macular degeneration and ataxia in three members of the same family, information about other relatives was sought (Fig. 1). A cousin of the great-great-grandmother of Case 1 
(generation A) was reported to have suffered from progressive unsteadiness in later middle life until the time she died, without impairment of vision, but no further details could be obtained.

The great-grandmother of Case 1 (generation B) became unsteady at the age of about 60 , and this gradually increased until she died at the age of 74 , her vision remaining intact. Her brother, the greatgreat-uncle of Case 1, was so unsteady by the age of 27 that he had to be admitted to a home for incurables. No defect of his vision was reported.

A great-uncle of Case 1, brother of Case 3, became unsteady at the age of 45 and became progressively disabled but is said to have retained good sight. The sibs of Cases 1 and 2 were examined but showed no evidence of defective vision or of ataxia. There was no evidence that relatives of the father of Case 1 had any neurological or ophthalmological abnormality.

\section{DISCUSSION}

Cerebro-retinal degeneration is uncommon in children and in adults, but a number of clinical syndromes in which it occurs have been recognized. The most clearly defined of these is infantile amaurotic idiccy, or Tay-Sachs disease. In this condition babies under the age of 1 year are affected by progressive macular degeneration, cessation of intellectual development, and eventually retrogression. Epileptic attacks are frequent and often take the form of generalized myoclonic jerks (infantile spasms). The mass reflexes of earliest infancy gradually reappear. A cherry red spot at the macula is characteristic of the syndrome.

Juvenile cerebromacular degeneration, affecting children between the ages of 5 and 8 years most commonly, was first described by Batten (1903a; 1914), though it is called the cerebroretinal degeneration of Spielmeyer and Vogt on the Continent. Commonly there is progressive visual failure with blindness within two years, epilepsy, progressive mental deterioration, paresis of the limbs, and ataxia. Death usually occurs within five or 10 years, though patients may survive for 20 years or more occasionally. The whole retina shows atrophy with pigmentation concentrated in and around the maculae in the juvenile form (Givner and Roizin, 1944; Sorsby, 1940; Wilson, 1954).

Cerebromacular degeneration similar to that described by Batten (1903a and b) may also occur in adult life. Adult patients have been reported by Kufs (1925, 1928, 1929), Torrance (1922), Oatman (1911), Schob (1912), Schaffer (1931), and Walter (1918). Not all these cases are well attested, but in general the retinal appearances are similar to those described by Batten and Mayou (1915). Ataxia is noted to be relatively more severe and mental deterioration less striking in adult patients by a number of authors, including Stewart (1937), Hassin (1926), Wyburn-Mason (1943), and Wilson (1954).

The problem of diagnosing the juvenile type of amaurotic family idiocy before the characteristic clinical features are present has interested a number of authors. Vacuolated lymphocytes similar to those found in many affected patients have been demonstrated in apparently healthy sibs, and abnormalities in the electroencephalogram have also been noted (Harlem, 1960). Unfortunately it is too early to assess the reliability of these findings as pointers to later cerebromacular degeneration. Neither Case 1 nor his mother (Case 2) showed vacuolated lymphocytes though these were sought.

Whereas infantile amaurotic idiocy appears to be much more prevalent in Jewish than Gentile patients, this is not so in the juvenile type. Mendelian recessive inheritance is almost invariable in the infantile form but not in the juvenile variety. Mendelian dominant inheritance seems to be infrequent, however, though it appears to be present in the family we report. A recessive inheritance, with Case 1 being homozygous and therefore the more severely affected, would be unlikely in the absence of evidence of abnormality in the father or his family.

Quantitative determinations of serum lipids and lipoprotein fractions in cerebromacular degeneration have variously shown a reduction in total lipids and phospholipids (Saifer, Aronson, Zymaris, and Volk, 1956)-or an increase in the low density lipoprotein fractions ( $\beta$ lipoproteins, $S_{f}$ (Goldman) 0-10), (Dargeon, Barclay, Calathes, and Brownell, 1958), but are thought to be of no diagnostic value (Fleischmajer, 1960). The values presented for Cases 2 and 3 are normal. Both values for serum cholesterol levels are at the upper limits of normal. Case 2 was pregnant when the examination was made.

The late infantile type of cerebromacular degeneration described by Bielschowsky (1920) shows many aetiological and clinical findings characteristic of both the infantile and juvenile types of cerebromacular degeneration. It seems likely that most, if not all the cases described as being of the 'late infantile type', can more accurately be classified as cases of infantile amaurotic family idiocy (Tay-Sachs disease) occurring at an unusually late age, or as cases of juvenile amaurotic idiocy (Batten's or SpielmeyerVogt's disease) beginning unusually early (WyburnMason, 1943).

The family reported contains six individuals affected by macular or cerebellar degeneration or a combination of both conditions and is similar to one mentioned by Walsh (1957) in which retinal or cerebellar degeneration were noted to occur either 
singly or in combination in different members. The fact that Case 1 showed features characteristic of the juvenile type at the age of a little more than a year provides further evidence that a proportion of the 'late infantile' cases described by Bielschowsky are, in fact, cases of so-called juvenile cerebromacular degeneration.

We are most grateful to Professor R. W. B. Ellis, Dr. Henry Miller, and Professor G. I. Scott who encouraged us to study and report these patients. Professor Scott very kindly examined the eyes of Case 1 and we are grateful to him and Miss C. Gundry of the Department of Ophthalmology for allowing us to reproduce the photographs they obtained.

\section{REFERENCES}

Batten, F. E. (1903a). Trans. ophthal. Soc. U.K., 23, 386.

- (1914). Quart. J. Med., 7, 444.

_, and Mayou, M.S.(1915). Proc. roy. Soc. Med., 8, Sect. Ophthal., p. 70 .
Batten, R. D. (1903b). Trans. ophthal. Soc. U.K., 23, 389.

Bielschowsky, M. (1920). J. Psychol. Neurol. (Lpz.), 26, 123.

Dargeon, H. W., Barclay, M., Calathes, D. N., and Brownell, M. J. (1958). J. Pediat., 52, 48

Fleischmajer, R. (1960). The Dyslipidoses. Thomas, Springfield, Illinois.

Givner, I., and Roizin, L. (1944). Arch. Ophthal. (Chicago), 32, 39.

Harlem, O. K. (1960). A.M.A. Amer. J. Dis. Child., 100, 918.

Hassin, G. B. (1926). Arch. Neurol. Psychiat. (Chicago), 16, 708.

Kufs, H. (1925). Z. ges. Neurol. Psychiat. (Orig.), 95, 169.

- (1928). Ibid, 117, 753.

(1929). Ibid, 122, 395.

Oatman, E. L. (1911). Amer. J. med. Sci., 142, 221.

Saifer, A., Aronson, S. M., Zymaris, M. C., and Volk, B. W. (1956) Proc. Soc. exp. Biol. (N.Y.), 91, 394.

Schaffer, K. (1931). Arch. Psychiat. Nervenkrank. (Chicago), 93, 767.

Schob, F. (1912). Z. ges. Neurol. Psychiat., 10, 303.

Sorsby, A. (1940). Brit. J. Ophthal., 24, 469.

Stewart, R. M. (1937). Proc. roy. Soc. Med., 30, 849.

Torrance, H. W. (1922). Glasg. med. J., 97, 193.

Walsh, F. B. (1957). Clinical Neuro-opthalmology, 2nd ed., pp. 670-671. Williams and Wilkins, Baltimore.

Walter, F. K. (1918). Z. ges. Neurol. Psychiat., 40, 349.

Wilson, S. A. Kinnier (1954), Neurology, 2nd ed., Vol. 2, Ed. Bruce A. N. Butterworth, London.

Wyburn-Mason, R. (1943). Brit. J. Ophthal., 27, 145. 